\title{
Consistent reactive participation of group members and reduction of intergroup conflict
}

\author{
DANIEL KATZ
}

University of Michigan

Our fundamental assumption is that there is no longer a rational basis for war or violent struggle between groups or nations because of conflicts of interest or of ideology. Violent solutions of such conflicts in the past are debatable as long-run solutions of competing interests, but, with the development of atomic and nuclear weapons, the common interest in survival has given reality to the pacifist's old contention about the ultimate absurdity of force as the solution of human problems. "The brotherhood of man," writes C. Wright Mills, "is now less a goal than an obvious condition of biological survival. Before the world is made safe again for American capitalism or Soviet communism or anything else, it had better be made safe for human life" (12).

Even before the development of modern weapons of total annihilation, conflicting groups have had much in common. In many wars soldiers had to be strictly enjoined from fraternizing with the nationals of the enemy state. Moreover, the conquering group did not always conquer permanently by force of arms if its cause was flagrantly unjust. Ideas of justice, of humanity, and of democracy have been strangely resistant to defeat on the field of battle. Common ideals are more often shared by the majority of warring groups than is generally realized. The fact that the leaders on both sides use much the same ideology to rationalize the role of their side in the conflict suggests that many of their followers need this reassurance about their own objectives. Thus we assume that, in spite of differences between groups in values and goals, there is sufficient community of interest to make resort to aggressive behavior an irrational means of conflict resolution.

\section{Causes of War: Background Factors}

Our analysis of the causes of war and group conflict will accordingly give greater emphasis to irrational forces as far as the great majority of people are concerned. Specific leaders and specific minority factions may on occasion be operating more on the model of Jeremy Bentham's utilitarian man, but, by and large, such a model is inadequate for an understanding of largescale conflict. An analysis of background factors basic to group conflict must recognize the differential motivational and cognitive processes of three groups: (1) the leaders, (2) the factions, and (3) the masses, as well as the interaction between these groups.

Six sources of irrationality can be recognized as common in many people: (1) latent hostility-the repression-projection syndrome; (2) situational frustration and dis- 
placed aggression; (3) defensive group identification; (4) institutional conformity (which need not necessarily be based upon defense mechanisms); (5) apathy or withdrawal, and (6) cognitive nearsightedness or shortsighted self-interest. These six factors vary in the degree of their direct relation to group conflict as will presently appear.

\section{LATENT HOSTILTTY}

The older instinctual doctrine had a ready answer for the satisfactions which people seem to find in expressing their hostility-namely, an innate need for aggression. A more complex explanation comes from the neo-Freudians, who describe a repression-projection syndrome (1). This syndrome develops from the frustrations which occur in the socialization process and the nature of the parent-child relationship. Children repress actions which are regarded as wicked, including acts of hostility toward parents-especially when the immediate personal environment of the child emphasizes the evil character of an act. But the wicked desires remain and are attributed to others, where they can be attacked and punished. Thus the extro-punitive person derives satisfactions of many sorts from conflict with members of an out-group. $\mathrm{He}$ is indulging his repressed interest in evil matters; he is salving his conscience by projecting his evil desires onto others and punishing the other person who is the true evildoer; and his repressed aggression finds release in meting out such punishment. Moreover, this way of releasing hostility may have sufficient libidinal investment as to produce sadistic tendencies. Reservoirs of repressed hostility of this sort have been one reason for mass attendance at public executions and contribute heavily to one type of crowd behavior. Any group-approved form of violence draws support from this source. It must be admitted, however, that modern institutionalized war may give less chance for the expression of these tendencies than the more personalized wars of an earlier period, where personal combat, looting, and rape were perhaps more common. But, even if war itself does not give much satisfaction to this motivation, it holds out exciting prospects in the preliminary period leading up to the outbreak of hostilities.

\section{SITUATION FRUSTRATION AND DISPLACED AGGRESSION}

The displacement of hostility on outgroups may often have its basis in genetically induced conflicts, as analytic theory suggests. But displaced aggression may also derive from the current deprivations and frustrations of adult life (4). The discontent in economic crises may lead to riots against minority groups. The scapegoating which occurs in this case is due to the failure to recognize the real cause of the deprivation in the social world. The situation may be too complex and the experience of people too slight to identify the frustrating agent. The difference between this situation-frustration and resulting displaced aggression and the personality-based conflict is that the first can be remedied by knowledge about the nature of the external world, whereas the second can be alleviated only by gaining an understanding of one's self or some self-insight into one's own conflicts (8). Though these two types are logically separable, they can be found together in the real world and can afford mutual reinforcement. Thus the person characterized by deep-lying hostility and extro-punitiveness, when further thwarted by his social world, can seek relief in aggression against some available out-group.

\section{DEFENSIVE GROUP DENTHFICATION}

Both the mechanisms described above have a natural outlet in aggression against 
other human beings. In addition, however, there is a defensiveness which is less directly related to overt group hostility. Because of insecurity in childhood, a deep inferiority conflict is created, and one mechanism for handling this conflict is to identify with numbers and with power. The group symbolizes both power and numbers, and, by regarding it as an extension of the self, the individual comes to share in its accomplishments. A victorious football team is a great asset to the egos of the members of the institution it represents. This emotional identification with the group sanctifies its actions and also demands competitive superiority of the group's actions. Moreover, the group symbols become so real to its people that action against a group symbol or a threat to a group symbol becomes a threat to the individual's own ego. In other words, defensive identification with the group has the function of giving the individual ego satisfactions that he cannot attain himself. When, however, the group itself suffers defeat, his situation becomes desperate. The Nazis came to power in Germany in good part by exploiting the national inferiority feelings of the German people. And the French continued their Algerian war in part because they could not accept the thought of sinking into the status of a third-rate power. Defensive group identification does not necessarily demand violent group struggle, since it can be satisfied in other ways, such as the conquest of outer space, competition to send up more, better, and bigger satellites. But it can contribute mightily to a war psychology under many circumstances.

\section{INSTITUTIONAL CONFORMITY}

It must also be recognized that there is a generalized conformity to institutional symbols representing legitimate authority which is not necessarily a matter of defense mechanisms. We all grow up in a world in which adaptive and instrumental learning will produce knowledge of the legitimate rules of the game. One type of role expectation has to do with the fact that there are duly constituted sources of authority which are to be obeyed in specific situations. We do not create our own world but adjust to the social realities already created.

And the social reality in which we find ourselves has us organized into role systems in which we obey group decisions and leadership decisions within certain limits. Moreover, this system of role relationships or institutions has a prearranged hierarchical set of conformities. At the apex is loyalty to the political state and obedience to its symbols. The political state alone of all institutions can inforce sanctions of physical coercion. The nation is so structured that the state has a monopoly of physical power, and the expectations are that the leaders will maintain and use this power. The citizens of the modern nation are involved in many groups, but their most potent involvement is in the political state, in that all other group allegiances must give way if in conflict with national allegiance. Treason in modern society is the greatest social crime, just as heresy was in an older period when the church was the dominant institution of the day. The machinery and symbols of the political state were created historically in war, conquest, confiscation, and exploitation. The police character of the state has been modified with the growth of democracy to include many social service functions, but its character as the most inclusive organization in society with a monopoly of physical force and its demands for first allegiance still remain.

The development of the state has been accompanied by an intensification of a fundamental perception of man about his social world. Men tend to see themselves and 
their kind as the figure against the background of outsiders (10). This in-groupout-group dichotomy is exploited and intensified by the state, which provides all the ready-made aids for such dichotomous thinking. The very structure of the state assumes external enemies, and to be a citizen member of a state carries the expectation of bearing arms against enemies. It is true that part of the state apparatus has to do with the peaceful mediation of the competing claims of subgroups within it, but an essential part of the state consists of the means for the mobilization of all its resources of economic and physical coercion against out-groups.

One source of war, therefore, lies in the habitual obedience of people to the symbols of political authority and in the acceptance of the superorganic character of national concepts and symbols (2). This habitual obedience often comes to be a blind obedience, not because people are showing identification with the aggressor, but because this is the common learned response to the situation. We are dealing, then, not with the irrationality of the defense mechanism but with a lack of discrimination in habitual responding to highly critical situations. With defense mechanisms, people give up some larger goal for immediate satisfactions. They escape the tension of the moment through involving themselves more deeply in other difficulties. With a blind habitual response, the effects may be the same, in that people do not assess the consequences of their behavior for anything but the momentary situation. But there are differences because there is an internal compulsion about defensive behavior which is lacking in the type of unquestioning obedience that we have been discussing. This latter type smooths the pathway for war because it helps to assure the acquiescence of masses of people for whom war itself is an evil.
The defensive mechanisms described above create more of a push in the direction of overt group conflict.

\section{APATHY AND WITHDRAWAL}

The complex nature of modern society and the complexity of its problems, the many and conflicting group demands upon the individual, the remoteness of the data he needs for meaningful decision-making and group participation from his everyday life, and the remoteness of his actions from the final group outcome all lead in one direction. This direction is withdrawing from the psychological field, or, as Robert Frost puts it, "Me for the hills where I don't have to choose." Apathy toward public affairs is characteristic of people in the large democratic states. In the Western democracies, only a small fraction of the people belong to political parties in the sense of participation in their activities. And the same lack of involvement of the many is found in almost all voluntary organizations and groups. This clears the way, then, for the motivated few to exercise a heavy influence upon the trend of affairs. The motivated few include both individual leaders of all groups and the heavily involved interest or ideological factions. These factions, moreover, are more frequently pushing some special interest of their own or some ideological position not necessarily in the public interest. There are groups from time to time which are motivated for a cause much broader than the segment of society they represent. But too often democratic functioning means that many special interests push their own causes, and the resulting compromises are deemed in the public interest. This outcome may be a far different public interest, however, than if the majority of the citizens had been motivated to pursue their common interest. 


\section{COGNITIVE NEARSIGHTEDNESS}

In dealing with defense mechanisms we are dealing with emotional compulsions which drive people from a consideration of social realities; in dealing with apathy we are confronted with a lack of motivation to examine the facts. There is another factor, however, which is more cognitive than motivational which comes between people and a realistic appraisal of their problems. It has to do with the law of least effort as it applies to cognitive processes. Human beings tend not to see beyond their noses. The immediate situation which confronts them is more important than related situations which they may experience tomorrow or the next day. A case study means more than rows of statistics. A concrete demonstration means more than the presentation of the scientific principles upon which the demonstration is based. The meaning of things is not examined very carefully with respect to their future or their past. This immediacy in living has many advantages, but it also may militate against a long-run intelligent course of conduct. Much of group and social policy has to have a larger frame of reference, both spatially and temporally. People will approve specific actions on a day-to-day basis and then be surprised at where the cumulation of these actions has taken them. If aggressive conflict and war are to be avoided, people need to consider the contribution which their daily actions make to this end result.

The apparent irrationality of human behavior may thus often result from a limited cognitive perspective rather than from a lack of logic. The standards people use in arriving at judgments are much more complete and differentiated in relation to decisions about their own personal affairs than they are about political and international issues. Hence their judgments in the former instance seem more sensible and more ra- tional to the observer. Many people who react in terms of blanket discrimination to the symbols which represent other ethnic groups will behave fairly and considerately in interpersonal relations with members of these groups (9). The expression "some of my best friends are . .." shows rationalization at its worst, but it also shows the double standard that people employ in personal, as against impersonal, relations.

The reason for the more adequate standards for judgments in the everyday affairs of the person is the continuing and detailed feedback from his reactions to this restricted environment. His perception and treatment of the men in his own work group immediately produce additional information, which becomes part of his cognitive structure. This flow of sensory feedback is not available to the individual with respect to the larger issues involving his nation. Hence his standards for making judgments about international matters or even national issues may be too vague and too fragmentary for decisions of discrimination and wisdom. Those who would remedy the matter by educational and informational efforts are on sound ground. The great weakness in this approach through information, however, is the failure to make such information functional to the average man in his daily mode of operating. Somehow the information must be a feedback in response to his own behavior rather than an educational program as such. Otherwise there is no correlation between the flow of information and the cognitive structures created in the minds of men (7).

\section{The Role of Leaders and Factions}

These factors, then, account for the involvement of people in group struggle when it is not to their rational interest to be so involved. They find themselves in war either 
because their emotions got in the way of intelligent behavior or because they withdrew from the field or because they took actions without considering the consequences. But most of these factors, while they describe the general conditions which make war possible, do not account for the dynamics of any specific conflict. Two other elements must be considered in the process: the role of leaders and the role of factions or leadership groups. Leaders may have the same defensive motivations as followers and, because of their leadership position, may move their countries to war or to the brink of war. Some of the Nazi leaders could be so characterized. But though in certain periods of history fanatical leaders of social movements may have deep needs for aggression, leaders in general show a more realistic motivation, a more rational and intelligent basis for their actions. They are motivated to stay in power and to maintain all the perquisites of their office; they may aspire to even higher positions in the leadership structure; and they may enjoy the challenge of their position. In general, then, they are not likely to indulge impulses which could make for self-destruction. They tend to weigh their decisions with respect to consequences. Nevertheless, such realistic appraisal is no guaranty of the peaceful outcome of the actions of leaders.

The problems of conflicting groups in his own country may be beyond the powers of resolution of the leader. He has no prospect of rising in the power structure or of holding his position in it by a genuine solution of such conflicts. Hence his own selfish interest may dictate a course which rallies the nation by capitalizing upon any conceivable threat to the nation from without. Orwell describes the technique of localized conflicts which keep totalitarian governments in power (13).

Moreover, leaders may appeal to the de- fensive behavior of potential followers in any situation where there is complexity, uncertainty, and confusion. The opposition party is the party of treason. It is a technique which will lose no votes and may gain some. In addition, leaders must show their basic membership character as representative of the nation, not only to appeal to more people but because, as leaders of the political state, people feel it is appropriate for their leaders to be patriots first and mediators of democratic competition between subgroups second. The common bond between all people in the national state is their identification with national symbols, with national interest, with national history. The leader of a nation can work for the specific realities behind these global emotional symbols, but in times of crisis it is easy to fall back upon the symbols themselves in their capacity to arouse defensive needs.

By "faction" or "leadership group" is meant the heavily involved minority, well organized to represent some interest or some ideological position. Such a faction is a leadership group in the sense that it exerts or may exert a great deal of influence upon national policy. Again its members may be motivated by defense mechanisms, but they can also be working rationally for their own narrow self-interest. The imperialistic ambitions of the oil interests are a case in point. Though we admit that conflicts between nations may arise out of such economic strivings, we deny that this type of rational self-interest is common enough to all members of one nation in competition with another to explain wars adequately on the basis of a rational model.

Another type of factional interest is commonly noted in groups which do not press for war but seek to expand their own roles. The branches of the military service push 
for the expansion of their own services and together press for the expansion of the military as against the civilian budget. And armament firms may have similar motivation to increase expenditures for their products. The military, however, is often interested more in the maintenance and growth of its own plant than in risking it in war. The German generals were enthusiastic about the support of the Hitler regime in developing the military might of Germany but were reluctant to take unnecessary chances with it. Thus, while some factional interests do not want violent struggle, they develop the machinery for making its occurrence highly probable.

Factions are of importance in national decisions not so much because they write their own ticket with respect to pushing their own narrow group interest as because the influence they exert may be disproportionate to their numbers. Any organized minority pressing for limited but clear objectives is a factor to be reckoned with in practical politics at almost all stages of the political process, from the initial stages of a leader's career to his major decisions when in office. The faction is always active and alert about its program; the masses become alert during crises when the choice of decisions has already been hopelessly narrowed. The doctrine of pluralism sees safety in the competition of many factions, so that labor unions, business groups, and farm organizations find some compromise that is within the public interest. But interest groups pushing for the expansion of the military or for the protection of oil interests in the Middle East have no counterpart in factions urging a program of peaceful solution. Though everyone has a stake in peace, such broad interests have no organization to counter the organized factions urging specific objectives which add up to a pattern of war.

\section{Types of Conflict Outcomes: Compromise versus Solution}

We have discussed the motivational forces and the cognitive processes which predispose toward aggressive outcomes of group conflict. In general, we assume that psychological processes which reflect the opposite dimension of these forces will make for non-violent solutions of group conflict. It is also necessary to consider the nature of types of conflict outcomes other than aggressive struggle, in relation to these positive and negative factors. Four types of conflict outcome should be distinguished, only one of which can properly be termed conflict solution or resolution (6). The first type is the stalemate of aggressive conflict in which there is no victory for either side but only a cessation due to exhaustion, with the prospect of renewed struggle over time. The second type is conquest and dominance, the direct result of successful aggressive struggle. This can give the temporary peace indicated by the Russian general who killed off the insurgents in Warsaw and then wired the czar, "Peace reigns in Warsaw." But this outcome was not then, and is not now, a solution of the conflict between Russia and Poland. Conflict solution requires an integration of the needs of both sides to the dispute so that they find a common path or a common goal without sacrificing their basic ethical principles. A common goal represents a shared objective of the majority members of both groups. A common path means that it sometimes is possible to find a course of action which will satisfy differing objectives. In some communities in the United States, white parents may object to integration of Negroes in the school, not because they are worried about social status implications, but because they are afraid of exposing their children to disease and to violence. An integrated pattern of schooling 
can be worked out which will meet these objections and still meet the needs of the Negroes for genuine integration. Often group conflict results from a failure to analyze carefully the real needs of both groups in the situation.

Between the domination outcome and the genuine solution of the group struggle stands a more ambiguous type of outcomethat of compromise. "Compromise" is used here in the true meaning of the term, namely, that the ethical principles of the contestants are compromised by the final modus operandi which is agreed upon. This is by far the most common type of outcome for both intranational and international conflict. It does not represent a true solution because the seeds of aggressive struggle still remain and the struggle is either continued at another time or displaced and appears in other group struggles. Negotiation from strength and appeasement are the two poles of the compromise technique. The test of whether or not the conflict has been compromised is to be found in the yielding by the conflicting parties of some essential principle of the social ethics of their group values.

Compromise rather than genuine solution, it must be admitted, is the common technique for adjusting group disputes in most of the civilized societies we know. It is especially effective within a nation where there is little possibility for recourse to open conflict. It is both a product and a cause of the crisscrossing of the interests of people in many subgroups within the national structure. Northern liberals may not become militant about the integration of Negroes in the American South because they are members of the Democratic party and so feel that they have to compromise with southern Democrats. The many points of commonality of interest between members of groups make these groups less militant about a single set of goals. The adjustment of group differences on the basis of these points of commonality can be integration or genuine conflict solution. But frequently it represents a compromise of the ethical principles of one or both groups.

Leaders can make a horse trade with leaders of a rival group both because they share some common points of interest with them as against their followers and because some faction within their own group could not be mobilized for a stand against the rival group. This faction may have too much in common with the particular rival group to back their leaders on the issues in question. Groups lack sufficient unity and homogeneity relative to the social context in which they operate to fight consistently for their values. The sharp schisms which might divide a nation into warring camps of social class against social class, one religion against another, and one geographical section against the other, are prevented because these lines of division cut across one another, as S. Rokkan has pointed out (14). The price that is paid, however, is to be found in unresolved problems, in apathy and withdrawal from realistic social participation and resulting international strife. The compromise technique within the nation often contributes to the militant action between nations.

\section{The Role of Consistent Reactive Participation in Group Decision by Group Members in Functional and Political Groups}

The genuine solution of group conflict both within the nation and between nations is facilitated by any conditions which minimize the role of the six causal factors previously described, as they operate both among leaders, factions, and followers. We shall concern ourselves, however, with only one major type of condition which has to 
do with the expression of positive forces, i.e., the counterpart of the factors making for hostile group action. This condition is the consistent participation of the many members in group processes and group decisions in their functional and political groups. Moreover, this condition of consistent participation refers to a reactive rather than to a passive role-to a qualitative more than a quantitative criterion. Membership behavior falls into four general types.

\section{TOKEN AND MINIMAL PARTICIPATION}

People may go through the minimal motions required of them as members of a group or as citizens. They may sometimes vote on election day, but they vote for a familiar name rather than for the merits of the candidate or for his principles and program. This is an expression of the apathy previously noted. It may be a psychological withdrawal based upon conflicted indecision - the inability to take a stand because of group pressures. Or it may be a truer form of anomie, in which the individual has been unable to form any real attachment to groups or subgroups. Token participation may also signify lack of involvement for the group in question but heavy involvement in other groups. Research findings, however, indicate that this is not the rule, for there is a good correlation between levels of activity by the same people in various groups (3).

\section{ROUTINE COMPLIANT PARTICIPATION}

Routine compliant participation is probably the most common form of group participation. People respond to the cues and suggestions from formal and informal leaders in routine fashion and show a very limited conception of their role. This is the pattern previously described as institutional conformity based upon our long training in accepting the rules of the game and the routine obedience to any form of legitimate authority. In any given group, however, routine compliance may represent the low involvement of the individual whose primary attachments are to other groups where he is anything but a compliant member.

\section{SPORADIC EMOTIONAL PARTICIPATION}

People will show intense emotional activity at certain times and for certain forms of group objectives. There may be a critical decision, as when a strike vote comes up in a union. Or the group may be functioning so poorly that an emergency situation is created. Or there may be certain types of group activity involving its emotional symbols which appeal to a certain type of follower. All these cases may provide opportunities for emotional expression by group members. Such expression may be based on defensive identification with the group or on the projection of repressed hostility or on need for excitement in an otherwise drab existence or on a belated recognition of problems and a symbolic dealing with them through intense emotional activity.

\section{CONSTSTENT REACTIVE PARTICIPATION}

Consistent reactive participation refers to involvement both over time and over a range of organizational programs. It means, too, that the individual is involved in the type of interaction in which he both receives and sends norms. In a political party or labor union, it refers to the small core of active workers who not only take responsibility for the organizational activities but mold party practice and policy by their suggestions and their active interpretation of the directions they receive.

A research program, then, might be directed at three major questions concerning consistent reactive group participation: (1) What patterns of personality and attitudinal 
and social structure variables maximize consistent reactive participation in functional and political groups? (2) What are the prior conditions for the creation and development of these factors which make for this type of group participation? (3) Under what conditions will this type of group participation lead to a reduction of aggressive group conflict and war?

We have already suggested some tentative answers to the first question but will proceed to make them more explicit. Answers to the second and third questions will not be attempted in this paper, but some of the assumptions basic to the third question will be considered.

\section{The Determinants of Consistent Reactive Participation by Group Members}

\section{PERSONALITY VARIABLES}

The personality pattern most productive of consistent reactive participation consists of ego-strength, self-understanding, empathic understanding, and social extroversion. People low in this constellation will more frequently show apathy, compliance, or sporadic participation. These three components are correlated, but the correlation is moderate rather than high. This pattern would constitute the democratic personality, in contrast to the authoritarian personality described by the California investigators (11).

A. Ego strength.-This concept describes the resourceful, secure person whose selfimage tends toward consistency and accuracy with respect to its social effects, who possesses confidence and tenacity, and who has developed the executive functions of the ego (skills for implementing his objectives).

B. Self-understanding.-The person high in ego strength is not torn by intense internal conflict, but he still may not be high in self-understanding. Self-insight refers to the understanding of one's own motivations.

C. Empathic understanding and the ability to deal with others.-Empathy does not mean sympathy with the plight of others but an understanding of their behavior through an imaginative living-through of something of the same processes. It is basic to co-operative working with others, in that it is the primary mechanism for achieving a shared understanding of experience.

D. Social extroversion.-The person who stands high in social extroversion is gregarious and outgoing and finds the process of doing things with others rewarding. Tannenbaum and Kahn, in their study of the participation patterns of union members, found that the active member has greater social drive but not greater need for social mobility (15). He has a high level of energy expenditure, which is socially directed.

\section{VALUE SYSTEMS}

The personality variables described above relate to contentless mechanisms of the person. They may predispose toward values of a given type, but they are not themselves identical with value systems. Value systems refer to affective organizations of beliefs which people hold about classes of objects or symbols.

A. Internalization of democratic and humanistic values.-Though the followers of ethical codes which assert the dignity of the human being have not always implemented these values in democratic practice, it is nonetheless true that such a philosophy provides the central reinforcement for our concept of consistent reactive participation. Perhaps in the past the emphasis has been too much on the protection of the person from infringement of his rights and too little upon his responsibility to assume an active role. The internalization we refer to would, however, include both the negative and the 
positive aspects of democratic functioning. Internalization of values can occur at two levels. The child incorporates the values that his parents hold through an identification with them resulting from both the need of their love and the fear of its loss. Internalization of values at the adult level is more difficult to achieve, but it can result from identification with a leader or from thorough involvement in some process to which such values are the necessary means.

B. Internalization of specific group goals of a positive social character.-From the motivational point of view, the taking-over by the individual of the goals of the group gives the dedication which makes for willingness to sacrifice for a cause. From a social point of view, it makes for clarity of the position of the group and so enables others to accept or attempt to modify this position.

\section{BELIEF SYSTEMS}

Reference is made here not to evaluations heavily loaded with affect but to cognitive functioning.

A. Realistic conception of institutional functioning as against belief in institutional fictions.-The realistic point of view would reject two current forms of the superorganic notion which have replaced the old belief in the divine character of the state. One is the mystical view of group action and official decisions as the immutable working of impersonal forces which are beyond the control of human beings. The other is the conception that the authorities, officials, and leaders have full and complete responsibility for public decisions and policies without the intervention or involvement of the people who make up the institution-"the littlepeople complex" often attributed to the German people. A people who see the institutional structure of which they are a part as existing independently of themselves and of having a life all its own are, in effect, surrendering their role in the decision-making process and are easily led into any form of institutional aggressiveness and struggle.

B. Belief in efficacy of individual action.This is closely related to a realistic concept of institutional functioning but is more specifically oriented to behavior. It can be considered the action orientation accompanying the belief system about the nature of institutions.

\section{SOCTAL STRUCTURE VARIABLES}

A. Source of power and locus of control in organizations.-Where power is vested in the membership of the organization, leaders have to validate themselves and their policies by votes of confidence from their followers. They can be turned out of office at the next election, as in political and labor organizations. In business and administrative structures, power is often vested in the top hierarchical group. The group may be the board of directors, who delegate the control function to some top executive. This second type of role structure makes for minimal participation on the part of the vast majority of members because there is nothing about which they have the power to make decisions. Business management often does not understand why its employees who have been treated well will prefer a trade union to the company union. The greater possibility for making decisions about their own welfare is, of course, a weighty consideration for the employees. The institutional location of power and control in an organization thus sets the limits for membership participation. In the hierarchical organization there will tend to be apathy about policies and defensive identification with its symbols.

B. Access to positions of power and privilege.-Though an organization may be hierarchical on the dimension of power, there still may be possibilities for upward mo- 
bility. Thus in a government administrative structure people may attain no decisionmaking status until they have reached a certain level in the hierarchy, but upward movement in the structure is possible. This openness of power positions counteracts the apathy of the hierarchical organization. The upwardly mobile keep informed and involved on matters of policy. How much mobility is necessary to preserve the belief that the able and loyal person will be rewarded by promotion depends upon many other factors, but often a small amount of real mobility will create a feeling of great openness of opportunity. On the other hand, where there is both a power monopoly in the structure and no upward mobility, the apathy of the members may turn into active estrangement and hostility (5).

C. Correlation between power, prestige, privilege, and skill gradients.-The role structure of organizations minimizes participation where there is a hierarchy of power which is correlated closely with privilege, prestige, and skill. In other words, if the people at the top of the hierarchy not only have the power but, in addition, have the interesting jobs and perquisites of office, there is little chance of involving people at the lower levels in the goals of the organization. Hence there is some advantage in some degree of separation of power, privilege, and skill gradients. The prestige gradient will not automatically follow the power gradient if there is such separation.

D. Institutional use of both common and differential roles. -If the organization puts all members into common roles almost exclusively, there is little utilization of differential talents of members and hence little personal reward for the exercise of their abilities. On the other hand, if there is no core of common roles, the internalization of group goals will decrease.

E. Character of multiple group member-
ships.-Individuals can belong to a number of groups and still participate consistently if the groups have the same general purposes and values, e.g., trade union, labor youth, labor party, socialist league. If multiple group memberships include groups of conflicting and competing objectives, then we get apathy, whereas similar groups can have a reinforcing effect upon consistent participation. Enough of an overlap of the same key personnel is required to reinforce and reward participation.

\section{Assumptions about the Relations of Participation to Group Conflict}

Consistent reactive participation has the following tendencies toward the solution of group conflict:

1. The power drives of leaders are checked. Absolute power corrupts absolutely and has dangerous potentialities for aggressive group action. Absolute power and reactive membership participation are opposed forces.

2. Leaders cannot take their people so readily into violent group struggle through the pressure of some special faction which sees profit in struggle or whose defensiveness is fed by conflict.

3. The instrumentality for constructive solutions for conflicts between groups cannot, as a rule, rise above the level of the instrumental functioning of the groups themselves. If a group normally operates through the blind compliance of the majority, the apathy of many and the emotional release of a minority, and the power motives of its leaders, it is not likely that its differences with other groups will be based upon the positive social values of the many. Water does not rise above its level.

4. The very nature of the basic objectives of the group are dependent upon the consistent reactive participation of the many. Group goals have taken on a positive social 
and ethical character with the growth of democracy. The divinity of kings, the exploitive police state, the authoritarian church, are not the products of an alert and widespread participation in group decisions.

5. The involvement of the many in reaching a solution of group differences makes possible a broader basis for finding common values and common paths. The people of two competing nations have more community of interest than have the active protagonists of conflict on either side.

\section{REFERENCES}

1. Adorno, T. W., Frenkel-Brunswik, E., Levinson, D., and SANFord, R. N. The Authoritarian Personality. New York: Harper \& Bros., 1950.

2. Allport, F. H. Institutional Behavior. Chapel Hill: University of North Carolina Press, 1933.

3. Axelrod, M. "Urban Structure and Social Participation," Sociological Review, XXI (1956), 13-18.

4. Berkowitz, L. "The Expression and Reduc- tion of Hostility," Psychol. Bull., LV (1958), 257-83.

5. CoHen, A. R. "Upward Communication in Experimentally Created Hierarchies," Human Relations, XI (1958), 41-54.

6. HoLt, E. B. The Freudian Wish. New York: Henry Holt \& Co., 1915.

7. Hyman, H. "Some Reasons Why Information Campaigns Fail," Public Opinion Quarterly, XI (1947), 412-23.

8. Katz, D., SarnofF, I., and McCuintock, C. "Ego-Defense and Attitude Change," Human Relations, IX (1956), 27-46.

9. LaPiere, R. T. "Attitudes vs. Actions," Social Forces, XIII (1934), 230-37.

10. Levinson, D. J. "Authoritarian Personality and Foreign Policy," Conflict Resolution, I (1957), 37-47.

11. _-_. "The Relevance of Personality for Political Participation," Public Opinion Quarterly, XXII (1958), 3-10

12. Mrlls, C. W., Nation, ClXXXVI, No. 10 (March 8, 1958), 202.

13. Orwell, G. 1984. New York: Harcourt, Brace \& Co., 1949.

14. RoKKan, S. Mimeographed paper presented at Oslo Seminar, April, 1958.

15. Tannebaum, A. S., and Kahn, R. L. Participation in Union Locals. Evanston: Row, Peterson \& Co., 1958. 